\title{
Authentic Leadership and Employee Voice: Roles of Obligation Perception and Power Distance Orientation
}

\author{
Hung-Yi Liao ${ }^{1} \&$ Kang-Hwa Shaw ${ }^{2}$ \\ ${ }^{1}$ Lecturer, Department of Human Resource Management, Shanghai Normal University, Shanghai, China \\ ${ }^{2}$ Lecturer, School of Management, Shandong University, Shandong, China \\ Correspondence: Kang-Hwa Shaw, School of Management, Shandong University, Shandong, China. E-mail: \\ kevinshaw99@sdu.edu.cn
}

Received: September 7, 2020 Accepted: September 25, 2020 Online Published: September 30, 2020

doi:10.5430/bmr.v9n3p25

URL: https://doi.org/10.5430/bmr.v9n3p25

\begin{abstract}
Based on social learning theory, this paper investigated the relationship between authentic leadership and employee voice as well as the mediating role of felt obligations for change, and the moderating role of power distance orientation. Using a questionnaire survey, we collected employee data in China, and obtained 183 usable responses to test our hypotheses. The results show that authentic leadership is positively related to employee voice, authentic leadership positively influences felt obligations for change, and felt obligations for change mediates the relationship between authentic leadership and employee voice. Further, power distance orientation moderates the influence of authentic leadership on felt obligations for change. Theoretical implications, managerial implications, and future directions are discussed.
\end{abstract}

Keywords: authentic leadership, felt obligation for change, power distance orientation, employee voice

\section{Introduction}

In a rapidly changing and increasingly complex organizational environment, organizations urgently need employees to express their voices to enhance creativity and performance. Employee voice is a kind of challenging positive behavior that can improve the operation of the organization. Moreover, it plays an important role in improving the efficiency of the organization's operation, performance, and its ability to prevent organizational crises (Helfrich \& Dietl, 2019). Therefore, how to enable employees to actively express their voices and participate in decision-making activities has become a key goal for maintaining the survival and development of an organization. Lin et al. (2019) believed that one of the important responsibilities of leaders is to boost employees' voices. In the organization, leaders have enormous resources and control rewards and penalties for employees, so the attitudes and behaviors of leadership are important factors affecting employee voice. Authentic leadership has been a focal area in the leadership field and has positive effects on managerial implications. Walumbwa et al. (2008) found that authentic leaders use their self-awareness, morality, balanced information processing, and relational transparency to improve the positive psychological states of members of the organization and create a leadership style that fosters a positive working climate in the organization. Studies have shown that authentic leadership has a positive impact on the operation of the organization, organizational commitment, and the behaviors of colleagues (Nasab \& Afshari, 2019). Therefore, the influence of authentic leadership on the active behaviors of organizational members has gradually become a research hotspot for scholars (Searle \& Barbuto, 2013), and employee voice is an important aspect of employees' active behaviors.

To follow this line of research, we take a subordinate-centered perspective to investigate the psychological process through which authentic leadership influences an employee's voice as well as one of the situational factors that might change this process. From this perspective, we can obtain a better understanding of how authentic leadership shapes employees' voices via the subordinates' self-concept. Specifically, we propose that authentic leadership could be positively related to employees' voices through the employee's felt obligation for change. Although felt obligation for constructive change has been examined as an individual difference in some studies (Fuller, Marler, \& Hester, 2006), one study has shown that felt obligation for constructive change is an important self-concept, which could be influenced by the work context (Culbert, 1974). Furthermore, we argue that power distance orientation, which refers to a subordinate's acceptance of inequality in the organization, could moderate the relationship between authentic leadership and felt obligation for change. Thus, we examine the mediating role of felt obligation for change and the 
moderating role of power distance orientation between authentic leadership and employee voice from a subordinate-centered perspective.

We extend the research on authentic leadership in three directions. First, drawing on social learning theory, we argue that authentic leadership might trigger employees' positive outcomes. Thus, it is reasonable to hypothesize that authentic leadership might have a positive effect on employee voice. Second, we contribute to the literature on authentic leadership by shifting the research focus from a positive psychology perspective to awareness of responsibility. Previous studies examined the mechanism between authentic leadership and employee voice from a positive psychology perspective, such as organization-based self-esteem (Liang, 2017). However, there is a paucity of research investigating the awareness of responsibility. Our study takes a subordinate-centered perspective to deepen our understanding of the relationship between authentic leadership and employee voice. Third, we extend the literature on authentic leadership by examining power distance orientation as a moderator. Our study enriches understanding of the complexities underlying employees' responses towards authentic leadership by proposing that employees' power distance orientation could improve their felt obligation for change.

\section{Theory and Hypotheses}

\subsection{Authentic Leadership and Employee Voice}

Authentic leadership, which combines the characteristics of transformational leadership and ethical leadership, is reflected in the improvement of leaders' self-awareness and internalized moral level, openness of the relationship with their employees, and an active leadership style that elevates the relationship with subordinates (Avolio et al., 2004). Employee voice refers to the ability of employees in the workplace to publicly express their own opinions on problems, including giving feedback on the behaviors or attitudes of others and solving work-related problems (Liang, Farh, \& Farh, 2012). Authentic leadership provides a positive role model, presenting self-consistency and altruistic behavior in the organization. Additionally, the core concept of authentic leadership encourages employees to find meaning in their work and follow their intentions and values to develop a behavioral style of "say all you know and say it without reserve" (Avolio \& Gardner, 2005). Authentic leadership enhances employees' ability to find self-esteem at work, without having to fear leadership authority and organizational pressure to express their opinions and ideas (Alvesson \& Einola, 2019).

Social learning theory refers to how individuals learn based on their own observations and how they use behavioral and learning experiences to shape their future behavior (Bandura, 1977). Individuals' social learning helps them to generate new patterns of behavior. Thus, employees will follow the role model of authentic leadership, thereby learning to express their true selves and actively sharing their ideas. Furthermore, authentic leadership would enhance the effectiveness of the leaders' behavior as a role model, which influences the social learning behavior of subordinates, and establishes a transparent and authentic organizational climate. Therefore, authentic leadership can create an outspoken climate to encourage employee voice. Prior work has shown that authentic leadership can influence employees' positive organizational behavior (Yammarinoet al., 2008), such as creativity (Regoet al., 2014), organizational citizenship behavior (Joo \& Jo, 2017), and voice behavior (Hsiung, 2012). Consequently, in this study, it was expected that authentic leadership would have a positive effect on employee voice. The more leaders lean toward authentic leadership, the more employees will give their suggestions. Thus, we proposed the following hypothesis:

\section{Hypothesis 1. Authentic leadership is positively related to employee voice.}

\subsection{Authentic Leadership and Felt Obligations for Change}

Felt responsibility is an important self-concept that reflects employees' perception of their responsibilities and obligations for the results of their work (Culbert, 1974). In contrast, felt obligation for change means that such responsibilities and obligations are more active. Additionally, it reflects individuals' willingness to not only make more effort to endure responsibilities and obligations but also actively improve the working process to set higher work goals. Compared with other leadership styles, authentic leadership is more conducive to the formation of employees felt responsibility.

Based on social learning theory, leaders are at the core of the organizational structure, and their traits and behaviors are often the objects of employee attention and learning. When employees observe the honest, fair, and courageous characteristics of authentic leadership, they will realize that these responsible behaviors are recognized and expected by the organization. According to the role model concept from social learning theory, these responsible behaviors will further become objects of employee learning and imitation, and thus employees will show proactive and responsible action (Mumford et al., 2002). Therefore, authentic leadership will stimulate employees' felt obligation for change through role models. Authentic leaders can express their values and positions so that employees can consider the 
situations in leadership positions and truly feel a sense of belonging in the workplace (Fuller et al., 2006). Thus, this study assumes that authentic leadership should have a positive influence on the felt obligation for change of employees. The more leaders tend to be authentic, the stronger the employees' felt obligation for change. according to the discussion above, we posit:

\section{Hypothesis 2. Authentic leadership is positively related to employees' felt obligation for change.}

\subsection{Mediating Role of Felt Obligation for Change}

In social learning theory, individuals improve their own behaviors through observation and learning (Bandura, 1977). Employees who adopt authentic leaders as role models learn to take responsibility for their own work performance and organizational development to develop their own felt obligation for change. Additionally, employees' felt obligation for change could enhance employee voice. Shinet al. (2019) stated that employees' intrinsic motivation for initiative can improve their performance: that is, employees' willingness to actively exert more effort in their work and achieve more than expected results. Felt obligation for change is the psychological state that reflects employees' intrinsic motivation to show initiative. This psychological state would encourage employees to view challenging behaviors, such as creativity and responsibility, as opportunities to improve the quality of their work, and it is more feasible for them to act. Felt obligation for change prompts employees to adopt constructive behaviors that they believe will benefit team members (Fuller et al., 2006). Employee voice is also a type of constructive behavior, manifested in employees expressing their ideas in public about problems in the workplace, including an understanding of ideas, behaviors, and solving work-related problems. Previous studies have shown that felt obligation for change is a key factor in the relationship between leadership styles and employees' extra-role behavior. For example, felt obligation for change mediates the effects of work environment on change-oriented organizational citizenship behavior (Choi, 2007), while servant leadership influences followers' voice via employees' felt obligation for change (Arain, Hameed, \& Crawshaw, 2019). Thus, this study assumes that authentic leadership will influence employee voice via felt obligation for change. Therefore, the following hypothesis was proposed:

Hypothesis 3: Felt obligation for change mediates the positive relationship between authentic leadership and employee voice.

\subsection{Moderating Role of Power Distance Orientation}

In previous research, cultural differences have been regarded as one of the boundary conditions for authentic leadership to affect employees' behaviors in the organization (Avolio et al., 2004). In this study, we discuss employees' power distance orientation as a power attitude in the organization, which belongs at the individual level. Power distance orientation refers to individuals' acceptance of unequal power distribution in the organization (Clugston, Howell, \& Dorfman, 2000). Employees with a high abide by the position gap between themselves and leaders. In the process of working with leaders, they are more willing to blindly follow the orders and decisions of their leaders and maintain a greater social distance from them. In this circumstance, the leadership behavior will be magnified by the employees, but it will help to demonstrate leadership effectiveness. Thus, employees with high power distance orientation are more likely to manifest authentic leadership behaviors, such as self-awareness, transparent relationships, and internalized morality. This will further strengthen employees' responsibility for organizational work and their felt obligation for change. Moreover, high power distance orientation will also be a catalyst for employees' sense of responsibility and strengthen the positive influence of leadership on employees' felt obligation for change. Previous studies also provided relevant evidence: for example, power distance orientation moderates the positive cross-level relationship between transformational leadership and procedural justice (Kirkman et al., 2009) and individual power distance orientation moderates the relationship between abusive supervision and employee job satisfaction (Lin, Wang, $\&$ Chen, 2013). Therefore, this study infers that power distance orientation will moderate the relationship between authentic leadership and employees' felt obligation for change. The greater the power distance orientation, the stronger the positive influence of authentic leadership on employees felt obligation for change. Therefore, the following hypothesis was proposed:

Hypothesis 4. Power distance orientation moderates the relationship between authentic leadership and employees' felt obligation for change.

The conceptual model of this study is shown in Figure 1. 


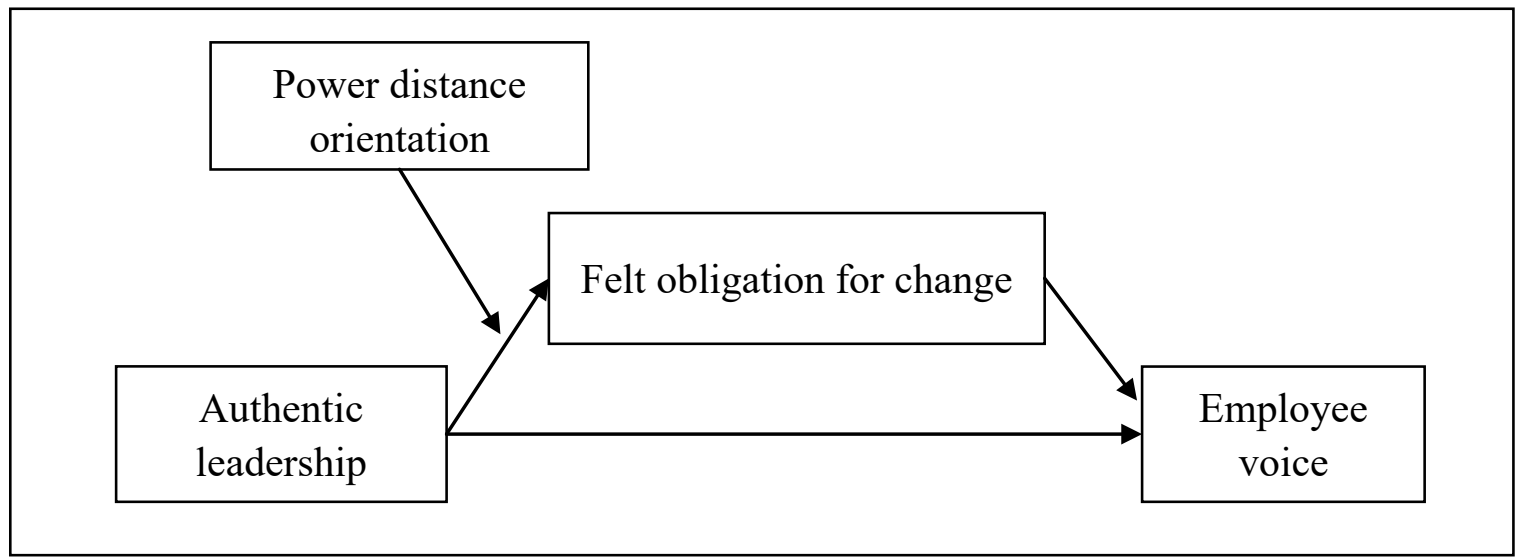

Figure 1. Conceptual model

\section{Method}

\subsection{Sample and Procedure}

The sample comprised full-time employees of several companies in Fujian, China. We examined the hypotheses using survey data from the questionnaires, which were distributed online through the researcher. After completing the online survey, each respondent returned it anonymously and directly to the authors. Finally, 183 valid questionnaires were collected. Among the respondents, $53.6 \%$ were female and $61.7 \%$ were college graduates. The age was mostly $20-30$ years $(63.9 \%)$ and the tenure was mostly $1-5$ years $(30.4 \%)$. In terms of company demographics, $67.8 \%$ of the respondents were from private enterprises and $19.1 \%$ were engaged in the financial industry.

\subsection{Measures}

Following the translation and back-translation procedure suggested by Brislin (1986), we created Chinese versions of the measures our variables. All items were assessed on a 5 -point Likert scale ranging from $1=$ strongly disagree to $5=$ strongly agree.

Authentic leadership was measured using the 14-item scale developed by Neide and Schriesheim (2011). Sample items included "My leader clearly states what he/she means." Cronbach's alpha for this scale was .93.

Felt obligation for change was measured using the 5-item scale developed by Morrison and Phelps (1999). Sample items included "I feel a personal sense of responsibility to bring about change at work." Cronbach's alpha for this scale was .86 .

Power distance orientation was measured using the 6-item scale developed by Dorfman and Howell (1988). Sample items included "A supervisor's use of authority and power is often necessary in order to assure that work is done efficiently." Cronbach's alpha for this scale was .84 .

Employee voice was measured using the 10-item scale developed by Liang et al. (2012). Sample items included "Make constructive suggestions to improve the unit's operation" and "Advise other colleagues against undesirable behaviors that would hamper job performance." Cronbach's alpha for this scale was .91.

As prior research has shown that some demographic characteristics may influence the extent to which individuals engage in voice behavior (Duan, Kwan, \& Ling, 2014; Xu et al., 2019), we controlled for these variables (i.e., gender, age, and tenure).

\section{Results}

\subsection{Measurement Model Analysis}

We tested a four-factor confirmatory factor analysis (CFA) model. Inspection of the fit indices indicated that the model had poor fitness $\left(\chi^{2} / \mathrm{df}=3.17, \mathrm{RMSEA}=.11, \mathrm{NFI}=.83, \mathrm{NNFI}=.86, \mathrm{CFI}=.88, \mathrm{IFI}=.88\right)$. The reason may be that we did not distinguish the sub-dimensions of authentic leadership and employee voice, but to maintain consistency with previous research we retained the original hypothetical model and analyzed authentic leadership and employee voice with the overall concept. We also built three competing models. The three-factor model combines authentic leadership 
and felt obligation for change into one factor, $\Delta \chi^{2}(1)=398.08, p<.01$. The two-factor model combines authentic leadership, felt obligation for change, and power distance orientation, $\Delta \chi^{2}(3)=951.10, p<.01$. The one-factor model combines all items into one factor, $\Delta \chi^{2}(10)=3814.69, p<.01$. The results showed that the proposed four-factor model provided a better fit to the data than these competing models, which further supports the discriminant validity of the four-factor model.

\subsection{Assessing Common Method Bias}

We conducted Harman's one-factor test using exploratory factor analysis for all the independent variables (except demographics) to check common method bias. The first factor accounted for only $29.69 \%$ of the total variance. No single major factor emerged to explain the majority of the variance involved in the model, and the result showed that no substantial common method bias existed in the data. As Harman's one-factor test and the CFA both showed, the variables were distinct; thus, common method bias may not be a serious issue in this study.

\subsection{Descriptive Statistics and Correlation Analysis}

Table 1 lists the means, standard deviations, and bivariate correlations of the variables. As expected, authentic leadership was positively correlated with employee voice $(r=.36, p<.01)$, authentic leadership was positively correlated with felt obligation for change $(r=.35, p<.01)$, and felt obligation for change was positively correlated with employee voice $(r=.66, p<.01)$. In addition, employee power distance orientation was negatively correlated with felt obligation for change $(r=-.17, p<.05)$.

Table 1. Means, Standard Deviations, and Correlations

\begin{tabular}{llllllllll}
\hline Variable & $M$ & $S D$ & 1. & 2. & 3. & 4. & 5. & 6. & 7. \\
\hline 1. Gender & 1.54 & 0.50 & - & & & & & & \\
2. Age & 2.48 & 0.91 & .01 & - & & & & \\
3. Tenure & 2.25 & 1.47 & -.03 & $.74^{* *}$ & - & & & \\
4. AL & 3.47 & 0.67 & $.15^{*}$ & .09 & .03 & - & & & \\
5. FC & 3.94 & 0.62 & .03 & $.21^{* *}$ & $.23^{* *}$ & $.35^{* *}$ & - & & \\
6. PD & 2.79 & 0.75 & -.04 & .00 & -.01 & .10 & $-.17^{*}$ & - & \\
7. EV & 3.64 & 0.60 & .04 & $.22^{* *}$ & $.24^{* *}$ & $.36^{* *}$ & $.66^{* *}$ & .05 & - \\
\hline
\end{tabular}

Note. $\mathrm{N}=183 . \mathrm{AL}=$ authentic leadership; $\mathrm{FC}=$ felt obligation for change; $\mathrm{PD}=$ power distance orientation; $\mathrm{EV}=$ employee voice. $* p<.05 ; * * p .01$.

\subsection{Tests of Mediating Effect}

As shown in Table 2, after controlling for the effects of demographic variables, authentic leadership had a positive influence on employee voice $(\beta=.35, p<.001)$ (Model 6); therefore, H1 was supported. Moreover, we can further see in Model 2 that authentic leadership had a positive influence on followers felt obligation for change $(\beta=.34, p<.001)$; therefore, $\mathrm{H} 2$ was supported. Finally, from Model 7, we can see that after felt obligation for change was added, the influence coefficients of authentic leadership on employee voice decreased $(\beta=.15, p<.05)$, while felt obligation for change still had a positive influence on employee voice $(\beta=0.58, p<.01)$. Thus, the indirect effects were significant; we concluded that felt obligation for change was a mediator between authentic leadership and employee voice. Therefore, H3 was supported.

\subsection{Tests of the Moderating Effect}

As shown in Table 2, after controlling for the effects of demographic variables, the regression coefficients of the interaction terms in Model $4(\beta=.14, p<.05)$ were significant. A simple slope test of the moderating effect showed that authentic leadership was positively related to felt obligation for change when power distance orientation was high $(\beta=.45, p<.01)$. When power distance orientation was low, the association between authentic leadership and felt obligation for change decreased significantly $(\beta=.22, p<.05)$. Although the simple slope test under both conditions is significant, but the difference test for the $\beta$ coefficient is significant $(\Delta \beta=.23, p<.05)$, showing that under the two power distance orientation of high and low, the slope of the two lines does differ significantly. These results indicate that the higher the power distance orientation of followers, the higher the possibility of increased felt obligation for 
change caused by authentic leadership. Power distance orientation can effectively enhance a number of positive consequences attributed to authentic leadership. Thus, H4 was supported.

Table 2. Results of the Hierarchical Regression Analysis

\begin{tabular}{|c|c|c|c|c|c|c|c|}
\hline \multirow{2}{*}{ Variable } & \multicolumn{4}{|c|}{ FC } & \multicolumn{3}{|c|}{ EV } \\
\hline & Model 1 & Model 2 & Model 3 & Model 4 & Model 5 & Model 6 & Model 7 \\
\hline \multicolumn{8}{|l|}{ Controls } \\
\hline Gender & .04 & -.02 & -.03 & -.03 & .05 & -.01 & .00 \\
\hline Age & .07 & .02 & .03 & .02 & .08 & .03 & .02 \\
\hline Tenure & .18 & $.20 *$ & $.19^{*}$ & $.20 *$ & .18 & $.21^{*}$ & .09 \\
\hline \multicolumn{8}{|l|}{ Predictors } \\
\hline $\mathrm{AL}$ & & $.34 * * *$ & $.36 * * *$ & $.36 * * *$ & & $.35 * * *$ & $.15^{*}$ \\
\hline $\mathrm{FC}$ & & & & & & & $.58 * * *$ \\
\hline PD & & & $-.20 * *$ & $-.25 * *$ & & & \\
\hline \multicolumn{8}{|l|}{ Interaction } \\
\hline $\mathrm{AL} \times \mathrm{PD}$ & & & & $.14^{*}$ & & & \\
\hline$R^{2}$ & .06 & .17 & .21 & .23 & .06 & .18 & .46 \\
\hline Adj. $R^{2}$ & .04 & .15 & .19 & .20 & .05 & .16 & .44 \\
\hline$\Delta R^{2}$ & $.06^{*}$ & $.11 * * *$ & $.04 * *$ & .02 & $.06^{* *}$ & $.12 * * *$ & $.28 * * *$ \\
\hline$F$ & $3.58 *$ & $9.07 * * *$ & $9.41 * * *$ & $8.61 * * *$ & $4.07 * *$ & $9.89 * * *$ & $30.12 * * *$ \\
\hline
\end{tabular}

Note. $\mathrm{N}=183 . \mathrm{AL}=$ authentic leadership; $\mathrm{FC}=$ felt obligation for change; $\mathrm{PD}=$ power distance orientation; $\mathrm{EV}=$ employee voice. ${ }^{*} p<.05 ; * *<.01 ; * * * p<.001$.

To further explore whether the interaction terms are in the hypothesized direction, we plotted the interaction effect in Figure 2.

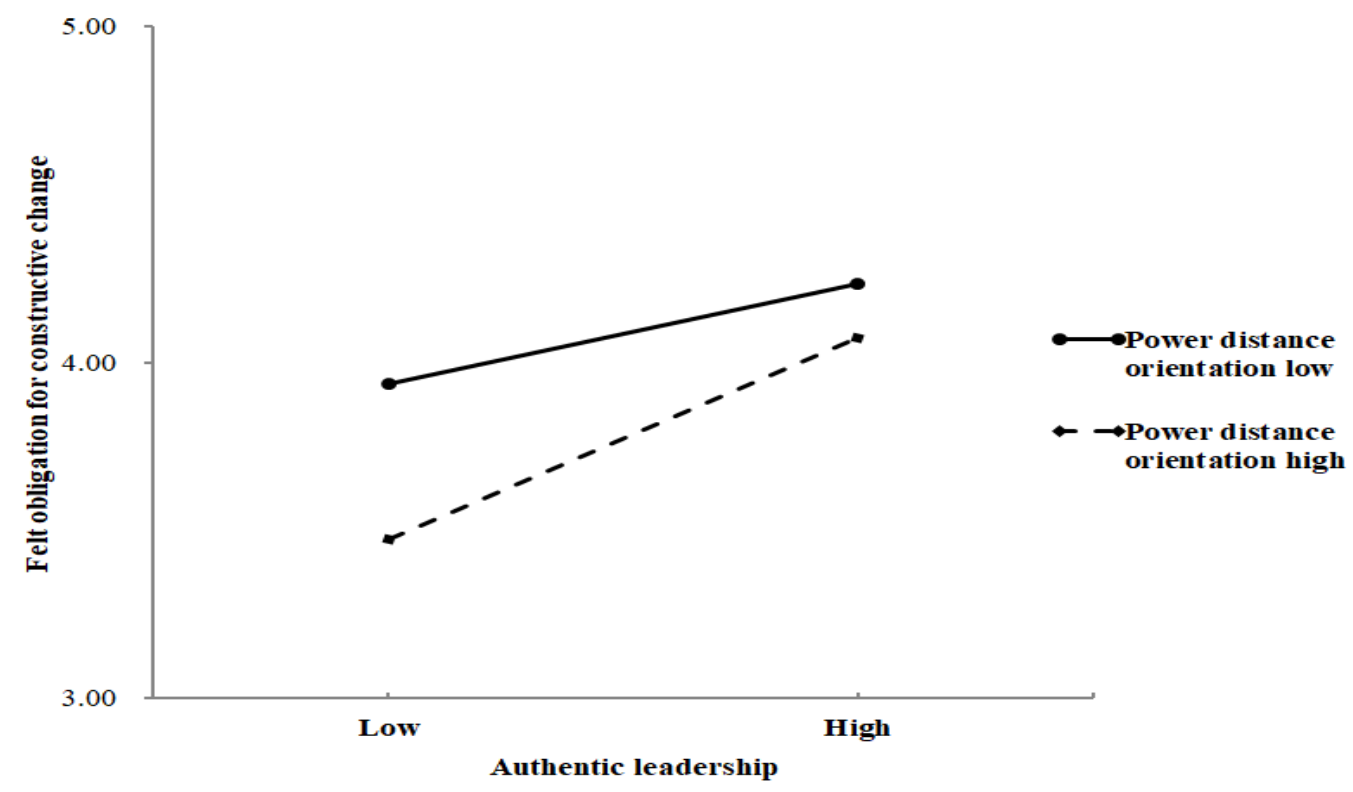

Figure 2. Interaction between authentic leadership and power distance orientation on felt obligation for change. 


\section{Discussion}

The primary goal of our study was to investigate how, why, and under what conditions authentic leadership might influence an employee's voice. In particular, we proposed and tested the mediating role of obligation perception and the moderating role of power distance. Our findings were as follows. First, our result is consistent with a previous study (Hsiung, 2012) that confirmed that authentic leadership influences employees' voices. Employee voice not only relies on cognitive style and personality but is also effectively stimulated by the context, especially direct leadership. Authentic leadership encourages employees to express their own ideas and accept their doubts, thereby promoting their voice. Our research verified the relationship between authentic leadership and employee voice and deepens the theoretical implication of authentic leadership.

Second, felt obligation for change mediated the relationship between authentic leadership and employee voice. We examined the mechanism of authentic leadership's influence on employee voice from the perspective of social learning theory. A proactive personal image of authentic leadership promotes employee learning and imitation and allows employees to take more responsibility for their work results and organizational development to enhance their felt obligation for change. This study enriches the research literature on social learning theory and provides a theoretical framework for the in-depth understanding of the mechanism of authentic leadership in employee voice.

Third, power distance moderated the relationship between authentic leadership and employees' felt obligation for change. This study explored the boundary condition of power distance in leadership effectiveness and showed that power distance affects the interaction between employee and leader in the process of employee voice. The results of this study show that under the situation of high power distance, employees are more likely to feel authentic leadership, that further enhances employees' sense of responsibility for their work and strengthens their felt obligation for change. Additionally, the context of high power distance also provides a catalyst for employees' responsibility and strengthens the positive influence of leadership on employees' felt obligation for change. We explained the specific organizational context to explore the moderating role of power distance between authentic leadership and felt obligation for change and this has a certain theoretical contribution to the leadership effectiveness of authentic leadership in the Chinese context.

\section{Managerial Implications}

Based on research results, the following suggestions are proposed for managers of organizations. First, strengthen cultivation of the manager's authentic leadership style. Managers should show an authentic leadership style as much as possible, express their interpersonal emotion, and encourage employees to speak up because they can pay attention to the feedback of subordinates and help employees to develop a positive working attitude. Therefore, we suggest that when recruiting managers, organizations can give priority to candidates with authentic leadership characteristics. Additionally, existing managers can also be trained and developed to strengthen the cultivation of their authentic leadership style in organizations. Second, improve employees' felt obligation for change. Employees with a felt obligation for change tend to show more constructive behaviors, including voice, which can contribute to the development and progress of the organization. Consequently, we suggest that managers in organizations should establish clear job responsibilities and assessment systems for employees. Furthermore, strengthen employees' job training to make them realize the importance of their work to the organization.

\section{Limitations and Future Directions}

There are some limitations to this study. First, this is a cross-sectional study; that is, the data collection of all variables was completed at the same time point, which does not allow causality to be inferred. Thus, it is suggested that future research can adopt a longitudinal study involving multiple time periods to enable causal relationships between variables to be inferred. Second, our study did not subdivide the sub-dimensions of authentic leadership and employee voice. Future research can analyze more clearly and deeply the impact of different dimensions of authentic leadership on different types of voice. Finally, in this research, we discussed the impact of the learning mechanism of authentic leadership on employee voice; subsequent research might examine the specific underlying psychological mechanisms (e.g., leader trust and psychological safety) and other boundary conditions (e.g., leader-member exchange).

\section{References}

Alvesson, M, \& Einola, K. (2019). Warning for excessive positivity: Authentic leadership and other traps in leadership studies. The Leadership Quarterly, 30(40), 383-395. https://doi.org/10.1016/j.leaqua.2019.04.001

Arain, G. A., Hameed, I., \& Crawshaw, J. R. (2019). Servant leadership and follower voice: The roles of follower felt responsibility for constructive change and avoidance-approach motivation. European Journal of Work and Organizational Psychology, 28(4), 555-565. http://doi.org/10.1080/1359432X.2019.1609946 
Avolio, B. J, \& Gardner, W. L. (2005). Authentic Leadership Development: Getting to the Root of Positive Forms of Leadership. The Leadership Quarterly, 16(3), 315-338. http:// doi.org/10.1016/j.leaqua.2005.03.001

Avolio, B. J., Gardner, W. L., Walumbwa, F. O., Luthans, F., \& May, D. R. (2004). Unlocking the mask: A look at the process by which authentic leaders impact follower attitudes and behaviors. Leadership Quarterly, 15(6), 801-823. https://doi.org/10.1016/j.leaqua.2004.09.003

Bandura, A. (1977). Self-efficacy: toward a unifying theory of behavioral change. Advances in Behaviour Research \& Therapy, 1(4), 139-161. http://doi.org/10.1037/0033-295X.84.2.191

Brislin, R. W. (1986). The wording and translation of research instruments. In W. J. Looner, \& J. W. Berry (Eds.), Field Methods in Cross-cultural Research (pp. 137-164). Beverly Hills, CA: Sage.

Choi, J. N. (2007). Change-oriented organizational citizenship behavior: Effects of work environment characteristics and intervening psychological processes. Journal of Organizational Behavior, 28, 467-484. https://doi.org/10.1002/job.433

Clugston, M., Howell, J. P., \& Dorfman, P. W. (2000). Does cultural socialization predict multiple bases and foci of commitment? Journal of management, 26(1), 5-30. https://doi.org/10.1177/014920630002600106

Culbert, S. A. (1974). The organization trap and how to get out of it. Basic Books.

Dorfman, P. W. \& Howell, J. P. (1988). Dimensions of national culture and effective leadership patterns: Hofstede revisited. In E.G. McGoun (Ed.), Advances in international comparative management: a research annual, 3(pp.127-149). Greenwich, CT: JAI Press.

Duan, J., Kwan, H. K., \& Ling, B. (2014). The role of voice efficacy in the formation of voice behaviour: A cross-level examination. Journal of Management \& Organization, 20(4), 526-543. DOI:10.1017/jmo.2014.40

Fuller, J. B., Marler, L. E., \& Hester, K. (2006). Promoting felt responsibility for constructive change and proactive behavior: Exploring aspects of an elaborated model of work design. Journal of Organizational Behavior, 27(8), 1089-1120. https://doi.org/10.1002/job.408

Helfrich, H., \& Dietl, E. (2019). Is employee narcissism always toxic? - The role of narcissistic admiration, rivalry and leaders' implicit followership theories for employee voice. European Journal of Work and Organizational Psychology, 28(2), 259-271. https://doi.org/10.1080/1359432X.2019.1575365

Hsiung, H. H. (2012). Authentic leadership and employee voice Behavior. A Multi-level Psychological Process. Journal of Business Ethics, 107(3), 349-361. https://doi.org/10.1007/s10551-011-1043-2

Joo, B. \& Jo, S. J. (2017). The effects of perceived authentic leadership and core self-evaluations on organizational citizenship behavior: The role of psychological empowerment as a partial mediator. Leadership \& Organization Development Journal, 38(3), 463-481. http://doi.org/10.1108/LODJ-11-2015-0254

Kirkman, B. L., Chen, G., Farh, J. L., Chen, Z. X., \& Lowe, K. B. (2009). Individual power distance orientation and follower reactions to transformational leaders: A cross-level, cross-cultural examination. Academy of Management Journal, 52(4), 744-764. https://doi.org/10.5465/amj.2009.43669971

Liang, J., Farh, C. I. C., \& Farh, J. L. (2012). Psychological antecedents of promotive and prohibitive voice: A two-wave examination. Academy of Management Journal, 55(1), 71-92. https://doi.org/10.5465/amj.2010.0176

Liang, S. G. (2017). Linking leader authentic personality to employee voice behaviour: A multilevel mediation model of authentic leadership development. European Journal of Work and Organizational Psychology, 26(3), 434-443. http:// doi.org/10.1080/1359432X.2017.1293656

Lin, W., Wang, L., \& Chen S. (2013). Abusive supervision and employee well-being: The moderating effect of power distance orientation. Journal Applied Psychology, 62(2), 308-329. https://doi.org/10.5465/amj.2010.0176

Lin, X., Chen, Z. X., Tse, H. H. M., Wei, W., \& Ma, C. (2019). Why and when employees like to speak up more under humble leaders? The roles of personal sense of power and power distance. Journal of Business Ethics, 158(4), 937-950. https://doi.org/10.1007/s10551-017-3704-2

Morrison, E. W. \& Phelps, C. C. (1999). Taking charge at work: extra role efforts to initiate workplace change. Academy of Management Journal, 42(4), 403-419. https://doi.org/10.5465/257011

Mumford, M. D., Scott, G. M., Gaddis, B., \& Strange, J. M. (2002). Leading creative people: Orchestrating expertise and relationships. The Leadership Quarterly, 13(6), 705-750. https://doi.org/10.1016/S1048-9843(02)00158-3 
Nasab, A. H., \& Afshari, L. (2019). Authentic leadership and employee performance: Mediating role of organizational commitment. Leadership \& Organization Development Journal, 40(5), 548-560. https://doi.org/10.1108/LODJ-01-2019-0026

Rego, A., Sousa, F., Marques, C., \& Pina e Cunha, M. (2014). Hope and positive affect mediating the authentic leadership and creativity relationship. Journal of Business Research, 67(2), 200-210. https://doi.org/10.1016/j.jbusres.2012.10.003

Searle, T. P. \& Barbuto, J. E. A. (2013). Multilevel framework expanding and bridging micro and macro levels of positive behavior with leadership. Journal of Leadership \& Organizational Studies, 20(3), 274-286. https://doi.org/10.1177/1548051813485133

Shin, Y., Hur, W. M., Moon, T. W., \& Lee, S. (2019). A motivational perspective on job insecurity: Relationships between job insecurity, intrinsic motivation, and performance and behavioral outcomes. International Journal of Environmental Research and Public Health, 16(10), 1812. https://doi.org/10.3390/ijerph16101812

Walumbwa, F. O., Avolio, B. J., Gardner, W. L., et al. (2008). Authentic leadership: Development and validation of a theory-based measure. Journal of Management, 34(1), 89-126. https://doi.org/10.1177/0149206307308913

Xu, M., Qin, X., Dust, S., \& DiRenzo, M. S. (2019). Supervisor-subordinate proactive personality congruence and psychological safety: A signaling theory approach to employee voice behavior. The Leadership Quarterly, 30(4), 440-453. http://doi.org/10.1016/j.leaqua.2019.03.001

Yammarino, F. J., Dionne, S. D., Schriesheim, C. A., \& Dansereau, F. (2008). Authentic leadership and positive organizational behavior: A meso, multi-level perspective. The Leadership Quarterly, 19(6), 693-707. https://doi.org/10.1016/j.leaqua.2008.09.004

\section{Copyrights}

Copyright for this article is retained by the author(s), with first publication rights granted to the journal.

This is an open-access article distributed under the terms and conditions of the Creative Commons Attribution license (http://creativecommons.org/licenses/by/4.0/). 